\title{
Hydrocarbon Selectivity Models for Iron-based Fischer-Tropsch catalyst
}

Tomasz Olewski ${ }^{1}$, Branislav Todic ${ }^{1,2}$, Lech Nowicki ${ }^{3}$, Nikola Nikacevic ${ }^{2}$, and Dragomir B. Bukur*, 1,4

${ }^{1}$ Chemical Engineering Program, Texas A\&M University at Qatar, PO Box 23874, Doha, Qatar

${ }^{2}$ Faculty of Technology and Metallurgy, University of Belgrade, Karnegijeva 4, Belgrade, Serbia

${ }^{3}$ Faculty of Process and Environmental Engineering, 90-924 Lodz, Poland

${ }^{4}$ Texas A\&M University, 3122 TAMU, College Station, Texas 77843, United States

*Tel.:+974-4423-0134.Fax: +974-4423-0065.Email: dragomir.bukur@qatar.tamu.edu 


\begin{abstract}
:
Two kinetic models of Fischer-Tropsch product selectivity have been developed based on reaction networks from the literature. The models were fitted to experimental data obtained using commercial iron-based catalyst in a stirred tank slurry reactor and under a wide range of process conditions. Results showed that both of the rival models were able to provide a satisfactory prediction of the experimental product distribution for n-parafin, 1- and 2-olefin. The simpler of the two models, a reaction network with a single type of active sites and solubility enhanced 1olefin readsorption term, was chosen as more adequate for practical use.
\end{abstract}

Keywords: Fischer-Tropsch synthesis; kinetic model; iron catalyst; product selectivity; olefin readsorption; 


\section{Highlights:}

- Selectivity model of FT synthesis for industrial iron catalyst was developed;

- Model considers formation of n-paraffin, 1-olefin and 2-olefin products;

- Experiments performed in a stirred tank slurry reactor over a range of conditions;

- Olefin readsorption and continued chain growth used to predict non-ASF behavior;

- Solubility enhanced olefin readsorption parameter $c$ obtained from VLE calculations; 


\section{Introduction}

One of the main ways for the production of synthetic hydrocarbon fuels is the FischerTropsch (FT) synthesis process, in which syngas is converted into liquid hydrocarbons over a solid catalyst. Feedstock for the production of syngas can come from several sources, so the FT process is an integral part of the XTL process (XTL = coal-, natural gas-, biomass-to-liquids). Catalysts used in the XTL processes are based on either iron or cobalt. Iron-based catalysts are the catalyst of choice for coal-to-liquids (CTL) process, because of their high activity in watergas-shift reaction (WGS) [1]. The two main reactions occurring over iron catalysts can be represented as:

$F T: C O+\left(1+\frac{m}{2 n}\right) H_{2} \rightarrow \frac{1}{n} C_{n} H_{m}+H_{2} \mathrm{O}$

$W G S: \mathrm{CO}+\mathrm{H}_{2} \mathrm{O} \leftrightarrow \mathrm{H}_{2}+\mathrm{CO}_{2}$

A considerable amount of work has been done on modeling of FT and WGS kinetics [2, 3]. The kinetic models of FT synthesis described in the literature may be classified into three categories: (1) Models for overall reactant consumption, (2) Models for hydrocarbon product distribution (selectivity models) and (3) Comprehensive (or detailed) kinetic models that describe both the overall reactant consumption and hydrocarbon formation rates. The simple reactant consumption models [3-6] are useful for initial design and reactor sizing. However, their inability to predict product distribution makes them less useful for more detailed reactor design considerations. This is why simple FT kinetic models are often used in combination with selectivity models in order to get the full set of information about the reactant and product formation rates [7]. 
The first attempt to describe the FT carbon number product distribution utilized the concept of polymerization reaction, which proceeds via addition of a single carbon number monomer. This is the so-called Anderson-Schulz-Flory (ASF) model, where mass balance for adsorbed species from the simplest reaction scheme with $\mathrm{n}$ carbon atoms in the molecule leads to the following equation [8]:

$\ln \left(y_{n}\right)=\ln (1-\alpha)+(n-1) \cdot \ln (\alpha)$

where $y_{n}$ is the molar fraction of products with $n$ carbon atoms and $\alpha$ is the growth probability factor. The ASF model assumes that $\alpha$ is independent of chain length, meaning that Eq. (3) results in a straight line with slope of $\ln (\alpha)$. It should be noted that the ASF equation does not distinguish between different product types as for instance 1-olefins, 2-olefins, n-paraffins and/or branched hydrocarbons. In addition FT product distribution typically deviates from the ASF prediction in terms of $\mathrm{C}_{1}$ (higher-than-expected), $\mathrm{C}_{2}$ (lower-than-expected) and increased growth probability with carbon number (i.e. higher-than-expected amount of heavy hydrocarbons) $[2,9$, 10]. These features of the product distribution are most often referred to as the non-ASF behavior.

The first explanations of non-ASF behavior were based on the so-called double- $\alpha$ hypothesis, which assumed that two distinct values of $\alpha$ exist due to availability of two types of active sites [11-13]. The existence of different oxide phases on Fe-based catalysts reinforced this concept $[11,12]$. However, observation of non-ASF behavior for Co catalyst, where FT occurs only on Co metallic sites brought this reasoning in question [14]. Additional feature of the FT product distribution is that olefin-to-paraffin ratio (OPR) exponentially decreases with carbon number. The double- $\alpha$ models typically do not differentiate between paraffin and olefin products, 
i.e. they only consider total hydrocarbons. A concept that offered explanation for both OPR and non-ASF features was olefin readsorption [15-17]. The initially formed 1-olefin molecules are known to participate in secondary reactions, one of which is readsorption followed by continued chain growth. If 1-olefin readsortion is set to be dependent of chain length, due to increase in concentration of 1-olefins with increase in molecular weight, both non-ASF and OPR can be predicted. This is related to increased residence time of larger molecules, which in turn is caused by their lower diffusivity, increased physisorption strength and increased solubility. Most of the selectivity models in the literature have used this concept and it provides a good prediction of experimental results [17-20].

More recently, the comprehensive kinetic models of FT based on LangmuirHinshelwood-Hougen-Watson (LHHW) approach, as well as models based on single-event methodology, have been examined in the literature [21-29]. However, hydrocarbon selectivity models have significantly higher precision in predicting product distribution for a given set of conditions and they have a smaller number of adjustable parameters than the comprehensive kinetic models.

The focus of the present study is on development of selectivity models for the prediction of FT product distribution, including n-paraffins and 1- and 2-olefins. Two models were derived using reaction networks of different complexity and including 1-olefin readsorption approach. The first model is based on the one-site Van der Laan and Beenakers' model [30] with the extension to 2-olefin formation, and the second model is a two-site model of Nowicki et al. [31]. Model derivation included a novel approach, i.e. reparameterization, which reduced the number of adjustable parameters of both models. In addition, the VLE calculation was conducted 
independently in order to determine the 1-olefin solubility parameter $c$, thereby removing the need for estimation of this parameter from the rates data.

\section{Experimental Procedures and Results}

Commercial precipitated iron FTS catalyst obtained from Ruhrchemie AG (OberhausenHolten, Germany) was used in this study. This catalyst (designated as LP 33/81) was used initially in fixed-bed reactors at Sasol in South Africa and its preparation procedure was described by Frohning et al. [32]. It has been tested extensively in our Laboratory [3, 20, 33, 34, 35], and was also used in previous studies of the kinetics of FTS by Lox and Froment [21] and Van der Laan and Beenackers $[30,36]$. Nominal composition of the catalyst is $100 \mathrm{Fe} / 5 \mathrm{Cu} / 4.2$ $\mathrm{K} / 25 \mathrm{SiO}_{2}$ (in parts per weight), whereas, its composition by atomic absorption spectrometry (AAS) was found to be $100 \mathrm{Fe} / 5 \mathrm{Cu} / 4 \mathrm{~K} / 27 \mathrm{SiO} 2$ [34]. Surface area and pore volume of calcined Ruhrchemie catalyst were $290 \mathrm{~m}^{2} / \mathrm{g}$ and $0.62 \mathrm{~cm}^{3} / \mathrm{g}$, respectively [34, 37].

Three tests (runs) were conducted in a $1 \mathrm{dm}^{3}$ stirred-tank slurry reactor (Autoclave Engineers). Details on the experimental set up, operating procedures, and product quantification can be found elsewhere $[3,32,37,38]$. Briefly, the feed gas flow rate was adjusted with a mass flow controller and passed through a series of oxygen removal, alumina, and activated charcoal traps to remove trace impurities. After leaving the reactor, the exit gas passed through a series of high and low (ambient) pressure traps to condense the liquid products. High molecular weight hydrocarbons (wax), withdrawn from a slurry reactor through a porous cylindrical sintered metal filter, and liquid products, collected in the high and low pressure traps, were analyzed by capillary gas chromatography (Varian 3400 gas chromatograph). Liquid products collected in 
the high and atmospheric pressure traps were first separated into an organic phase and an aqueous phase and then analyzed using different columns and temperature programmed methods (Varian 3400 gas chromatograph). The reactants and noncondensible products leaving the ice traps were analyzed with an on-line gas chromatograph (Carle AGC 400) with multiple columns using both flame ionization and thermal conductivity detectors.

The Ruhrchemie catalyst (11-25 g) was calcined in air at $300^{\circ} \mathrm{C}$ and a sample with a size fraction between 140-325 mesh (44 - $105 \mu \mathrm{m})$ was loaded into the reactor filled with 300-320 g of Durasyn 164 oil (a hydrogenated 1-decene homopolymer, $\sim \mathrm{C}_{30}$ obtained from Albermarle Co.). The catalyst was pretreated in $\mathrm{CO}$ at $280^{\circ} \mathrm{C}, 8 \mathrm{bar}$, and $3 \mathrm{NL} / \mathrm{g}$-cat/h (where, NL/h, denotes volumetric gas flow rate at $0^{\circ} \mathrm{C}$ and 1 bar) for 12 hours. After the pretreatment, the catalyst was tested initially at baseline conditions of $260^{\circ} \mathrm{C}, 15 \mathrm{bar}, 4 \mathrm{NL} / \mathrm{g}$-Fe/h using CO-rich synthesis gas $\left(\mathrm{H}_{2} / \mathrm{CO}\right.$ molar feed ratio of $\left.2 / 3\right)$. After reaching a stable steady-state value ( $\sim 60 \mathrm{~h}$ on stream), the catalyst was tested at different process conditions $\left(\mathrm{T}=220,240\right.$ and $260^{\circ} \mathrm{C}, \mathrm{P}=8,15,22.5$ and 25 bar, reactant feed ratios 0.67 and 2, and flow rates from 0.52 to $23.5 \mathrm{NL} / \mathrm{g}-\mathrm{Fe} / \mathrm{h}$ resulting in a wide range of $\mathrm{CO}$ conversions $9-84 \%$ ). The minimum length of time between changes in process conditions was $20 \mathrm{~h}$. In total 25 sets of data at different process conditions were obtained in three separate runs, involving 10, 7 and 8 mass balances, respectively (Note that Run 1 includes 12 mass balances, where MB 7 and 10 are replicates of baseline conditions). The conditions and selected results are summarized in Table 1. Mass and atomic closure $(\mathrm{C}, \mathrm{H}, \mathrm{O})$ were within $100 \pm 5(\%)$.

Initial catalyst activity at the baseline conditions (55-78 h on stream) was very reproducible in all three tests with the same batch of catalyst as can be seen from Table 1. Variations in lumped hydrocarbon selectivity were more pronounced, but were not significant. Baseline 
conditions were periodically repeated in all three runs in order to assess the extent of catalyst deactivation. Catalyst activity ( $\mathrm{CO}$ conversion) decreased in all three runs, but the product distribution was not affected significantly by catalyst deactivation as can be seen from data presented in Table 1 and as discussed in more details elsewhere $[38,39]$. It should be noted that data presented in Table 1 do not reflect only changes in product distribution caused by catalyst deactivation, but also experimental errors associated with collection of liquid products and wax (mass of products collected) and their quantification. An appropriate range of catalyst particle sizes (i.e., diameters of 44-105 $\mu \mathrm{m})$ and a high impeller speed (1200 rpm) were selected to minimize physical transport resistances, allowing for intrinsic kinetic measurements. The data were analyzed assuming perfectly mixed flow reactor behavior.

\section{Hydrocarbon selectivity model of FT synthesis}

Hydrocarbon formation reaction rates can be calculated by considering reaction networks for formation of hydrocarbons. This calculation can be done separately from the consumption and formation of inorganic components (consumption of $\mathrm{CO}$ and $\mathrm{H}_{2}$, formation of water and the water-gas shift reaction) with an assumption that hydrocarbons are formed on active sites different than those for the WGS reaction. This type of model leads to parameters which lump together reaction rate constants and surface concentrations of reaction intermediates. Therefore, model parameters will depend on reaction conditions (temperature, pressure and space velocity) and need to be estimated for every set of process conditions. A number of models of this type exist in the literature for iron-based FT catalysts [20, 30, 31, 36, 40]. 


\subsection{Reaction networks for selectivity modeling}

Two hydrocarbon formation models have been considered in the present study: an expanded model of Van der Laan and Beenackers $[30,36]$ and a model proposed by Nowicki et al. [31]. Reaction networks for these two models are shown in Figure 1.

Van der Laan and Beenackers $[30,36]$ proposed a simple scheme (Figure 1a), which included chain growth, termination to n-paraffin and 1-olefin and readsorption of 1-olefin followed by their continued chain growth. This model is known as olefin readsorption product distribution model (ORPDM). They estimated parameters of the model from data obtained in a spinning basket reactor using the Ruhrchemie catalyst. In this work we extended the original ORPDM by considering 2-olefin formation, which is schematically represented in the right hand side of Figure 1a, for $\mathrm{n} \geq 4$.

Nowicki et al. [31] developed a selectivity model based on a more complex reaction network (Figure 1b) which included a second type of active sites for FT reaction $\left(\mathrm{S}_{2}\right.$ in Figure 1b). This model also allowed for secondary 1-olefin hydrogenation and isomerization to 2olefins, as well as readsorption and continued chain growth on the second type of sites.

The two reaction networks shown in Figure 1 were used to derive equations for formation rates of n-paraffins, 1- and 2-olefins, and the parameters were estimated from experimental data. Model discrimination is based on the quality of fit and consideration regarding complexity of the model (i.e. total number of parameters).

\subsection{Model derivation, parameters and equations}

Figure 1a shows the reaction network of hydrocarbon formation of modified ORPDM. Chain growth initiates on the first type of active sites $\left(\mathrm{S}_{1}\right)$ by hydrogenation of adsorbed 
monomer $\left(\mathrm{CH}_{2}-\mathrm{S}_{1}\right)$ to adsorbed methyl group $\left(\mathrm{CH}_{3}-\mathrm{S}_{1}\right)$. Chain propagation occurs via insertion of adsorbed monomer into adsorbed alkyl species $\left(\mathrm{C}_{\mathrm{n}} \mathrm{H}_{2 \mathrm{n}+1}-\mathrm{S}_{1}\right)$, which can terminate to paraffin $\left(\mathrm{C}_{\mathrm{n}} \mathrm{H}_{2 \mathrm{n}+2}\right)$ by hydrogenation, and to 1-olefin $\left(1-\mathrm{C}_{\mathrm{n}} \mathrm{H}_{2 \mathrm{n}}\right)$ or 2-olefin $\left(2-\mathrm{C}_{\mathrm{n}} \mathrm{H}_{2 \mathrm{n}}\right)$ by dehydrogenation. The $\alpha$ - and $\beta$-olefins (1- and 2-olefins) are considered separately. According to the reaction network, 1-olefin can readsorb which leads to adsorbed alkyl species, which can than either propagate or terminate. The selectivity of products $\mathrm{C}_{1}$ and $\mathrm{C}_{2}$ is being considered separately and therefore their kinetic parameters are different than for other hydrocarbons. This is due to the well-known deviations in product distribution for methane and ethylene.

The kinetic equations for this model can be formulated based on the reaction network from Figure 1, followed by the reaction rates from Table 2, and the above-mentioned assumption that selectivity of products $\mathrm{C}_{1}$ and $\mathrm{C}_{2}$ are considered separately.

The model yields pseudo-rate constants of reactions $(\lambda)$, which incorporate the true kinetic constants $(k)$ and surface concentrations of reaction intermediates $(\theta)$. The denotation of particular $\lambda$ constants is shown in Table 2 . The model has 11 parameters: 10 pseudo-rate constants $(\lambda)$ and constant $\mathrm{c}$, which is introduced in the following equation (5).

Surface concentration of 1-olefin $\left(C_{1-C_{n} H_{2 n}}^{S}\right)$ can be eliminated following the procedure similar to that used by Van der Laan and Beenackers [30]. The assumption is made that the reaction rate of 1-olefin is proportional to its partial pressure in the gas phase in an ideally mixed continuous reactor:

$$
\begin{aligned}
& R_{1-C_{N} H_{2 n}}=P_{1-C_{N} H_{2 n}} \cdot \frac{S V}{R_{g} \cdot T} \\
& n \geq 2
\end{aligned}
$$


and that the partial pressure and concentration of $1-\mathrm{C}_{n} \mathrm{H}_{2 n}$ species on the surface can be connected by Henry's constant, $\mathrm{He}\left(\mathrm{C}_{\mathrm{n}} \mathrm{H}_{2 \mathrm{n}}\right)$, assuming vapor-liquid equilibrium (VLE):

$$
\begin{aligned}
& P_{1-C_{N} H_{2 n}}=C_{1-C_{N} H_{2 n}}^{S} \cdot H e_{1-C_{N} H_{2 n}}=C_{1-C_{N} H_{2 n}}^{S} \cdot a \cdot \exp (-c \cdot n) \\
& n \geq 2
\end{aligned}
$$

Here it is assumed that Henry's constant exponentially changes with chain length. Then the relationship between the concentration of olefin on the surface and its reaction rate can be written as:

$$
\begin{aligned}
& C_{1-C_{N} H_{2 n}}^{S}=R_{1-C_{N} H_{2 n}} \cdot \frac{R_{g} \cdot T}{a \cdot S V} \cdot \exp (c \cdot n) \\
& n \geq 2
\end{aligned}
$$

Since the rate of 1-olefin formation is:

$$
\begin{aligned}
& R_{1-C_{N} H_{2 n}}=\lambda_{t, 1 o} \cdot \theta_{C_{N} H_{2 n+1}-S_{1}}-\lambda_{r, 1 o}^{*} \cdot C_{1-C_{N} H_{2 n}}^{S} \\
& n \geq 2
\end{aligned}
$$

by replacing Eq. (6) into (7) and rearranging, we get the expression for the rate of 1-olefin formation in which the liquid concentration of 1-olefins $\left(C_{1-C_{N} H_{2 n}}^{S}\right)$ is eliminated:

$$
\begin{aligned}
& R_{1-C_{N} H_{2 n}}=\frac{\lambda_{t, 1 o} \cdot \theta_{C_{N} H_{2 n+1}-S_{1}}}{1-\lambda_{r, 1 o}^{*} \cdot \frac{R_{g} \cdot T}{a \cdot S V} \cdot \exp (c \cdot n)} \\
& n \geq 2
\end{aligned}
$$

The number of model constants $(\lambda)$ can be reduced by simple reparameterization with reference to the termination of paraffin $\left(\lambda_{t, p}\right.$ and $\left.\lambda_{s t, p}\right)$, which simplifies the model and numerical calculations. Additionally the termination to ethene is related to ethane and 1-olefin. The above 
reparameterization reduces the number of parameters and leads to the following pseudoconstants $\kappa$. The final model has 8 parameters (including parameter $c$ ):

$\kappa_{1}=k_{1} \cdot \theta_{\mathrm{CH}_{2}-S_{1}} \cdot \theta_{H-S_{1}}$

$\kappa_{p}=\frac{k_{1} \cdot \theta_{C H_{2}-S_{1}}}{k_{t, p} \cdot \theta_{H-S_{1}}}$

$\kappa_{t, p}^{(1)}=k_{t, p}^{(1)} / k_{t, p}$

$\kappa_{t, p}^{(2)}=k_{t, p}^{(2)} / k_{t, p}$

$K_{1 o}^{(2)}=\frac{k_{t, p}^{(2)}}{\left(k_{t, p}\right)^{2}} \cdot \frac{k_{t, 1 o} \cdot a \cdot S V}{k_{r, 1 o}^{(2)} \cdot\left(\theta_{H-S_{1}}\right)^{2} \cdot R_{g} \cdot T}$

$K_{1 o}=\frac{1}{k_{t, p}} \cdot \frac{k_{t, 1 o} \cdot a \cdot S V}{k_{r, 1 o}^{(2)} \cdot\left(\theta_{H-S_{1}}\right)^{2} \cdot R_{g} \cdot T}$

$\kappa_{t, 2 o}=\frac{k_{t, 2 o} \cdot \theta_{S_{1}}}{k_{t, p} \cdot \theta_{H-S_{1}}}$

After introduction of new parameters, defined in eqs. (9) to (15), modified Van der Laan and Beenackers model rate equations are:

$R_{C H_{4}}=\kappa_{t, p}^{(1)} \cdot \frac{\kappa_{1}}{\kappa_{p}+\kappa_{t, p}^{(1)}}$

$R_{C_{2} H_{6}}=\kappa_{t, p}^{(2)} \cdot \frac{\kappa_{1}}{\kappa_{p}+\kappa_{t, p}^{(1)}} \cdot \alpha_{2}$ 


$$
\begin{array}{ll}
R_{C_{n} H_{2 n+2}}=\frac{\kappa_{1}}{\kappa_{p}+\kappa_{t, p}^{(1)}} \cdot \prod_{i=2}^{n} \alpha_{i} & \mathrm{n} \geq 3 \\
R_{C_{2} H_{4}}=K_{10}^{(2)} \cdot \exp (-2 c) \cdot \frac{\kappa_{1}}{\kappa_{p}+\kappa_{t, p}^{(1)}} \cdot \alpha_{2} & \\
R_{1-C_{n} H_{2 n}}=K_{1 o}^{(2)} \cdot \exp (-c \cdot n) \cdot \frac{\kappa_{1}}{\kappa_{p}+\kappa_{t, p}^{(1)}} \cdot \prod_{i=2}^{n} \alpha_{i} & \mathrm{n} \geq 3 \\
R_{2-C_{n} H_{2 n}}=\kappa_{t, 20} \cdot \frac{\kappa_{1}}{\kappa_{p}+\kappa_{t, p}^{(1)}} \cdot \prod_{i=2}^{n} \alpha_{i} & \mathrm{n} \geq 4
\end{array}
$$

where growth probabilities can be calculated as:

$$
\begin{aligned}
& \alpha_{2}=\frac{\kappa_{p}}{\kappa_{p}+\kappa_{t, p}^{(2)}+K_{1 o}^{(2)} \cdot \exp (-2 c)} \\
& \alpha_{3}=\frac{\kappa_{p}}{1+\kappa_{p}+K_{1 o} \cdot \exp (-3 c)} \\
& \alpha_{n}=\frac{\kappa_{p}}{1+\kappa_{p}+\kappa_{t, 2 o}+K_{1 o} \cdot \exp (-c \cdot n)}
\end{aligned}
$$

More details on the model derivations can be found in the Supplementary materials.

Similar procedure for model derivation and parameter reduction was also employed by Nowicki et al. [31]. As explained above this model allows for hydrogenation of readsorbed 1-olefins on a secondary type of sites. In addition, 2-olefins are formed only on secondary sites. These additional reactions are described in Table 3 . The equations of this model can be found in the Supplementary material section. 


\subsection{Use of VLE calculation to estimate parameter $c$}

A key term in kinetic model equations needed to predict the non-ASF behavior and an exponential decrease in olefin-to-paraffin ration is $\exp (c \cdot n)$ [25]. In section 3.2 we showed how this term can be derived using solubility enhanced 1-olefin readsorption concept, by associating it with Henry's constant through:

$$
H e_{1-C_{n} H_{2 n}}=a \cdot \exp (-c \cdot n)
$$

where $a$ and $c$ positive constants. This dependency was used to obtain the formula for liquid phase concentrations of 1-olefins (i.e., Eq. (6)).

In the initial parameter estimation, parameter $c$ was one of the model parameters that was estimated from the experimental product distribution data. However this parameter can also be calculated using vapor-liquid equilibrium (VLE) data. This is done by approximation of VLE results $(K$-values) as follows:

$$
K_{1-C_{n} H_{2 n}}=\frac{y_{1-C_{n} H_{2 n}}}{x_{1-C_{n} H_{2 n}}}=\frac{a}{P} \cdot \exp (-c \cdot n)
$$

where $y_{1-C_{n} H_{2 n}}$ and $x_{1-C_{n} H_{2 n}}$ are molar fractions in the vapor and liquid phase and $P$ is total pressure. The above equation can be linearized as:

$$
\ln \frac{y_{1-C_{n} H_{2 n}}}{x_{1-C_{n} H_{2 n}}}=\ln \frac{a}{P}-c \cdot n
$$

In order to get these values and the corresponding $K_{1-C_{n} H_{2 n}}$, the calculation of VLE was performed for the entire system (including $\mathrm{C}_{1-20}$ n-paraffins, $\mathrm{C}_{2-20}$ 1-olefins, $\mathrm{C}_{4-17}$ 2-olefins, 
lumped hydrocarbons $\mathrm{C}_{21+}$ component and inorganic species $\mathrm{CO}, \mathrm{H}_{2}, \mathrm{H}_{2} \mathrm{O}$ and $\mathrm{CO}_{2}$ ). In this work we applied the modified Peng-Robinson equation of state (PR EoS). Two modifications to PR EoS were included to improve the PR EoS ability to predict the behavior of inorganics in a mixture including heavy hydrocarbons. First modification was the use of Li and Froment $[38,44]$ equation for the calculation of the acentric factor function for inorganic species. Second, the binary interaction factors $k_{i j}$ were estimated utilizing experimental data from literature on solubility of inorganic species in various hydrocarbons [38]. The critical properties and acentric factor $\omega$ of inorganic species and linear paraffins and olefins (up to $\mathrm{C}_{20}$ ) were taken from Poling et al. [45] and Nikitin et al. [46]. For higher molecular weight hydrocarbons $\left(>C_{20}\right)$ the equations of Gao et al. [47] were used. The critical temperature and pressure of the start-up fluid (Durasyn) were estimated from Joback's group contribution methods [48], whereas the acentric factor was estimated using Lee and Kessler equation [49].

\subsection{Parameter estimation}

The parameters of two models were estimated and tested using the experimentally obtained product distribution data. In total 25 mass balances (see Table 1) at different conditions were used in parameters estimation. The objective function for this estimation was:

$$
S=\sum_{h=1}^{N_{\text {resp }}} \sigma^{h, h} \sum_{i=1}^{N_{\text {exp }}}\left(\hat{R}_{i, h}-R_{i, h}\right)^{2}
$$

where $\hat{R}_{i, h}$ and $R_{i, h}$ are experimental and calculated rates of species $i$ in balance $h, \sigma^{h, h}$ are weight factors, $N_{\text {resp }}$ and $N_{\exp }$ are number of responses and experiments, respectively. The following responses are used: twenty paraffins $\left(\mathrm{C}_{1-20}\right)$, nineteen 1-olefins $\left(\mathrm{C}_{2-20}\right)$, fourteen 2olefins $\left(\mathrm{C}_{4-17}\right)$ (seventeen 2-olefins $\mathrm{C}_{4-20}$ are shown in figures) and pseudo-component $\mathrm{C}_{21+}$. The weight factors for different species were calculated based on three replicate experiments (initial 
baseline conditions in three runs) and represent the diagonal elements of the inverse of covariance matrix [40].

\section{Results and discussion}

\subsection{Selectivity models with parameter $c$ estimated from experimental data}

The results of the two selectivity models (extension of Van der Laan and Beenackers model and Nowicki et al. model) have been compared. Goodness of fit for those models expressed via mean absolute relative residual (MARR) is shown in Table 4. The comparison of MARR values for the two models shows that modified Nowicki et al. model provides a better fit of the data at all tested temperatures. However, the quality of model fit is very similar and differences between them are typically smaller than $5 \%$. This allows us to choose the simpler model, i.e. modified Van der Laan and Beenackers model (ORPDM), as the preferred one. The simplicity of ORPDM is reflected mainly in the fact it uses only 8 parameters, compared to 16 parameters in Nowicki et al. model. In other words, complex two-site model was not able to provide a significant improvement in the model predictions compared to a simple one-site model and introduces higher complexity and requires longer computational time. Product distributions for n-paraffin, 1- and 2-olefin at one of the tested conditions for both models tested is shown in Figure 2. The fitting and parameter values for ORPDM are discussed in detail below.

Out of the eight ORPDM parameters two, $\kappa_{t, p}^{(1)}$ and $\kappa_{t, p}^{(2)}$, are temperature dependent only, whereas the remaining ones depend on all reaction conditions. The summary of estimated parameters is given in Table 5. Statistics for the obtained pseudo-constants of the model (expressed as $t$-values) show good significance for all parameters ( $t$-values are given in Table A1 
of the Supplementary material). This indicates that all of the parameters are important and required in the kinetic model equations.

The parity plot for total hydrocarbons is shown in Figure 3. A comparison of calculated and experimental olefin to paraffin and 2-olefin to total olefin ratios is shown in Figure 4. Very good agreement was obtained between the calculated product distribution and the corresponding experimental values (Figures 2-4). Especially good agreement was obtained for all 1- and 2olefins as well as for $\mathrm{C}_{1-15} \mathrm{n}$-paraffin. This is consistent with results that were previously reported for Van der Laan and Beenackers model $[30,36]$.

It should be noted that in some cases large deviations from expected trends in the experimental points were observed. This is related to difficulties associated with experimental analysis of FTS products. These deviations are observed especially for 2-olefins in $\mathrm{C}_{5-8}$ and nparaffins in $\mathrm{C}_{17-25}$ carbon number ranges. The first deviation might be caused by difficulty/errors in combining results from three gas chromatographic analyses for components in this range. The deviations in the second range $\left(\mathrm{C}_{17-25}\right)$, observed for $\mathrm{n}$-paraffin, might be caused by lower sensitivity of analysis for these components (those were the last components that were detected). This may be attributed to the effect of hydrocracking of heavier molecules due to the presence of acid sites on Fe-based FT catalyst [42]. A recent study of Gao et al. [43] showed that some of unexpected positive deviations in $\mathrm{C}_{15}-\mathrm{C}_{25}$ carbon number range can be explained by accumulation of water in hot traps. In addition, even bigger deviations between values predicted by the model and experimental data are observed for heavier hydrocarbons (paraffins $\mathrm{C}_{21+}$ ). Several reasons might cause these deviations. The first one is related to withdrawal of wax (liquid phase from the reactor) through internal filter element, which might cause fluctuations and errors in the amounts of wax collected (e.g. incomplete wax withdrawal during a mass 
balance or higher than the actual amount produced during another mass balance period). The second reason is associated with wax analysis and separation of its components. All of the above mentioned experimental artifacts had an effect on parameter estimation and reduced the model precision.

Some groups of components that are formed during the FT reaction, namely gasoline and diesel oil, are interesting from the practical point of view, therefore ability of the model to predict the amount of these products is of importance. All products obtained during the FT synthesis can be divided into five groups: methane, light gases $\mathrm{C}_{1-4}$ hydrocarbons, gasoline $\left(\mathrm{C}_{5-}\right.$ 12), diesel oil $\left(\mathrm{C}_{13-20}\right)$ and wax $\left(\mathrm{C}_{21+}\right)$. Very good agreement is obtained for methane, light gases, gasoline and diesel oil for which almost all MARR values for different mass balances are within $35 \%$. A bigger discrepancy is observed only for wax (MARR 70\%) and as it was mentioned, this might be caused by errors in wax withdrawal. The total amount of wax is relatively small in comparison to other component (less than $1 \%$ in moles and $5 \%$ in weight). Therefore, it has a very small impact on the total amount of hydrocarbon production, as shown on the parity plot of total hydrocarbon reaction rate (Figure 3), where calculated quantities are in good agreement with experimental measurements (total MARR less than 20\%). The exponential decrease of 1olefins and an increase in 2-olefin formation with carbon number are very well predicted (Figure 4).

\subsection{Selectivity model with parameter c estimated from VLE}

After the values of $y_{1-C_{n} H_{2 n}}$ and $x_{1-C_{n} H_{2 n}}$ were determined from VLE, it was possible to estimate the value of parameter $c$ in equation (27). This VLE determined constant related to 1olefin solubility can then be introduced into the hydrocarbon selectivity model, therefore reducing the number of parameters that need to be estimated. Comparison showed that the 
parameter $c$ estimated from VLE is about $1.5-2$ times greater (with the average of 1.63) compared to the one estimated from reaction results using hydrocarbon selectivity model. Similar observation was made by Schulz et al. [18]. Thus, it is expected that the other parameters of selectivity model will differ, especially parameters related to 1-olefin formation $K_{10}$ and $K_{10}^{(2)}$, as well. Therefore, the model parameters were estimated again utilizing the parameter $c$ obtained from VLE calculations. New parameter values are given in Table 6 . The parity plot of lumped reaction rates using new values of parameters is shown in Figure 5. In general, the use of c values estimated from VLE calculations results in small changes of model parameters except for $K_{1 o}$ and $K_{1 o}^{(2)}$. However, these changes have an insignificant impact on the overall result hydrocarbons reaction rates, as shown in Figure 5. The hydrocarbon selectivity model still offers almost identical predictions compared to the model in which parameter $c$ was estimated from experimental data, with MARR values of $12.7,6.1,10.1,19.6$ and 71.8 for methane, $\mathrm{C}_{2-4}, \mathrm{C}_{13-20}$ and $\mathrm{C}_{21+}$, respectively.

\section{Conclusions}

Two FT product selectivity kinetic models were developed based on reaction network from the literature (modification of Van der Laan and Beenackers' and Nowicki et al. models [30-31]) and compared. Model parameters were estimated from experiments in a stirred tank slurry reactor over a wide range of process conditions. Comparison of results showed that the two models predict experimental data well, with small differences in goodness of the fitting. Our modification of Van der Laan and Beenackers' one-site model provides good fit of the data and it contains fewer parameters than a two-site model of Nowicki et al. This model predicts that the chain growth parameter $(\alpha)$ and olefin to paraffin ratio are dependent on carbon number, which arises from readsortion of 1-olefins onto primary FT reaction sites. The addition of secondary 
active sites (as in reaction network of Nowicki et al.) did not significantly improve the quality of model prediction. Readsorption of initially formed 1-olefins was, through the exponential dependence of Henry's constant with chain length, related to their solubility. The parameter $c$, which describes exponential dependency of 1-olefin solubility, was estimated from experimental data assuming vapor-liquid equilibrium. Comparison showed that parameter $c$ estimated from VLE calculations is about $1.5-2$ times greater (with the average value of 1.63) than the one estimated by fitting hydrocarbon selectivity model to the experimental data. This has an impact on numerical values of parameters related to 1-olefin formation $K_{10}$ and $K_{1 o}^{(2)}$, but it has no significant effect on the overall result and hydrocarbon reaction rates. It is therefore recommended to use the model in which parameter $\mathrm{c}$ is independently estimated from VLE, since this decreases the number of adjustable model parameters.

\section{References}

[1] F.G. Botes, J.W. Niemantsverdriet, J. van de Loosdrecht, Catal Today 2013, 215, 112-120, DOI: 10.1016/j.cattod.2013.01.013

[2] G.P. van der Laan, A.A.C.M. Beenackers, Catal. Rev. - Sci. Eng. 1999, 41, 255-318, DOI: $10.1081 / C R-100101170$

[3] W.H. Zimmerman, D.B. Bukur, Can. J. Chem. Eng. 1990, 68, 292-301, DOI: $10.1002 /$ cjce. 5450680215

[4] R.B. Anderson, Kinetics and reaction mechanism of the Fischer-Tropsch synthesis, Catalysis 1956, 257-371.

[5] B.W. Wojciechowski, Catal. Rev. 1988, 30 (4), 629-702, DOI:10.1080/01614948808071755

[6] B. Sarup, B.W. Wojciechowski, , Can. J. Chem. Eng. 1989, 67, 62-74, DOI:

$10.1002 /$ cjce. 5450670110

[7] A. Rafiee, M. Hillestad, Comput. Chem. Eng. 2012, 39, 75-83, DOI:

10.1016/j.compchemeng.2011.11.009 
[8] R.B. Anderson, R.A. Friedel, H.H. Storch, J. Chem. Phys. 1951, 19, 313-319, DOI: $10.1063 / 1.1748201$

[9] M. Claeys, E. van Steen, Stud. Surf. Sci. Catal. 2004, 152, 601-680.

[10] C.H. Bartholomew, R.J. Farrauto, Reactors, Reactor Design, and Activity Testing -

Fundamentals of Industrial Catalytic Processes, 2 ed., John Wiley \& Sons, New Jersey 2006 [11] G.A. Huff, Jr., C.N. Satterfield, J. Catal. 1984, 85, 370-379, DOI: 10.1016/00219517(84)90226-4

[12] R.A. Dictor, A.T. Bell, J. Catal. 1986, 97 (1), 121-136, DOI: 10.1016/0021-9517(86)900436

[13] B. Sarup, B.W. Wojciechowski, Can. J. Chem. Eng. 1988, 66, 831-842, DOI: $10.1002 /$ cjce. 5450660518

[14] G. Botes, Ph.D. Thesis, Technische Universiteit Eindhoven, Eidhoven 2008.

[15] E.F.G. Herington, The Fischer-Tropsch synthesis considered as a polymerization reaction, Chem. Ind. 1946, 346-347.

[16] S. Novak, R.J. Madon, H. Suhl, J. Catal. 1982, 77 (1), 141-151, DOI: 10.1016/00219517(82)90154-3

[17] E. Iglesia, S.C. Reyes, R.J. Madon, J. Catal. 1991, 129 (1), 238-256, DOI: 10.1016/00219517(91)90027-2

[18] H. Schulz, M. Claeys, Appl. Catal., A 1999, 186 (1-4), 91-107, DOI: 10.1016/S0926860X(99)00166-0

[19] E.W. Kuipers, C. Scheper, J.H. Wilson, I.H. Vinkenburg, H. Oosterbeek, J. Catal. 1996, 158 (1), 288-300, DOI: 10.1006/jcat.1996.0028

[20] W. Zimmerman, D. Bukur, S. Ledakowicz, Chem. Eng. Sci. 1992, 47 (9-11), 2707-2712, DOI: 10.1016/0009-2509(92)87117-9

[21] E.S. Lox, G.F. Froment, Ind. Eng. Chem. Res. 1993, 32 (1), 71-82, DOI:

10.1021/ie00013a011

[22] Y.-N. Wang, W.-P. Ma, Y.-J. Lu, J. Yang, Y.-Y. Xu, H.-W. Xiang, Y.-W. Li, Y.-L. Zhao,

B.-J. Zhang, Fuel 2003, 82 (2), 195-213, DOI: 10.1016/S0016-2361(02)00154-0

[23] J. Yang, Y. Liu, J. Chang, Y.-N. Wang, L. Bai, Y.-Y. Xu, H.-W. Xiang, Y.-W. Li, B.

Zhong, Ind. Eng. Chem. Res. 2003, 42 (21), 5066-5090, DOI: 10.1021/ie030135o

[24] B.-T. Teng, J. Chang, C.-H. Zhang, D.-B. Cao, J. Yang, Y. Liu, X.-H. Guo, H.-W. Xiang, Y.-W. Li, Appl. Catal., A 2006, 301 (1), 39-50, DOI: 10.1016/j.apcata.2005.11.014

[25] B. Todic, T. Bhatelia, G.F. Froment, W. Ma, G. Jacobs, B.H. Davis, D.B. Bukur, Ind. Eng.

Chem. Res. 2013, 52 (2), 669-679, DOI: 10.1021/ie3028312

[26] B. Todic, W. Ma, G. Jacobs, B.H. Davis, D.B. Bukur, Cat. Today 2014, 228, 32-39, DOI:

10.1016/j.cattod.2013.08.008

[27] G. Lozano-Blanco, J.W. Thybaut, K. Surla, P. Galtier, G.B. Marin, Ind. Eng. Chem. Res.

2008, 47 (16), 5879-5891., DOI: 10.1021/ie071587u

[28] G. Lozano-Blanco, K. Surla, J.W. Thybaut, G.B. Marin, Oil Gas Sci. Technol 2011, 66, 423-435, DOI: 10.2516/ogst/2009075

[29] B. Todic, T. Olewski, N. Nikacevic, D.B. Bukur, Chem. Eng. Trans. 2013, 32, 793-798, DOI: 103303/CET1332133

[30] G.P. van der Laan, A.A.C.M. Beenackers, Ind. Eng. Chem. Res. 1999, 38, 1277-1290, DOI: 10.1021/ie980561n

[31] L. Nowicki, S. Ledakowicz, D. B. Bukur, Chem. Eng. Sci. 2011, 56 (3), 1175-1180, DOI: 10.1016/S0009-2509(00)00337-7 
[32] C.D. Frohning, W. Rotting, F. Schnur, J. Falbe (Ed.), Chemierohstoffe aus kohle, Thieme, Stuttgart, 1977, p. 234.

[33] Bukur, D. B., Patel, S. A. and X. Lang, App. Catal. 1990, 61 (1), 329-349, DOI:

10.1016/S0166-9834(00)82154-5

[34] D. B. Bukur, L. Nowicki, R. K. Manne, X. Lang, J. Catal. 1995, 155, 366-375.

[35] W. P. Ma, Y. Ding, V. Carreto-Vazquez, D. B. Bukur, Appl. Cat. A 2004, 268, 99-108.

[36] G.P. van der Laan, A.A.C.M. Beenackers, Stud. Surf. Sci. Catal. 1998, (119), 179-184, DOI: 10.1016/S0167-2991(98)80428-X

[37] D. B. Bukur, L. Nowicki, S. A. Patel, Can. J. Chem. Eng. 1996, 74 , 399-404.

[38] T. Olewski, Ph.D. Thesis, Technical University of Lodz, Poland 2008.

[39] D. B. Bukur, G. F. Froment, T. Olewski, Final Report, U. S. DOE Grant No. DE-FG2600NT41540, 2007.

[40] L. Nowicki, D.B. Bukur, Stud. Surf. Sci. Catal. 2001, (136), 123-128, DOI: 10.1016/S01672991(01)80291-3

[41] K.B.B. Gilbert F. Froment, Juray De Wilde, Chemical Reactor Analysis and Design, 3 ed., John Wiley \& Sons, New Jersey 2011.

[42] D.B. Bukur, X. Lang, Ind. Eng. Chem. Res. 1999, 38 (9) 3270-3275, DOI:

10.1021/ie990028n

[43] J. Gao, B. Wu, L. Zhou, Y. Yang, X. Hao, J. Xu, Y. Xu, Y. Li, Ind. Eng. Chem. Res. 2012, 51 (36) 11618-11628, DOI: 10.1021/ie201671g

[44] Y.-W. Li, G.F. Froment, ARSOFTS: Advanced Reactor Simulation of Fischer-Tropsch Synthesis, in, Laboratorium voor Petrochemische-Techniek, Rijksuniversiteit, Gent, Belgium, 1996.

[45] R.C. Reid, J.M. Prausnitz, B.E. Poling, The Properties of Gases and Liquids, MacGraw Hill, 1987.

[46] E.D. Nikitin, P.A. Pavlov, A.P. Popov, Fluid Phase Equilib. 1997, 141 (1-2), 155-164, DOI: 10.1016/S0378-3812(97)00202-1

[47] W. Gao, R.L. Robinson, K.A.M. Gasem, Fluid Phase Equilib. 2001, 179 (1-2), 207-216, DOI: 10.1016/S0378-3812(00)00498-2

[48] K.G. Joback, R.C. Reid, Chem. Eng. Commun. 1987, 57 (1-6), 233-243, DOI:10.1080/00986448708960487

[49] B.I. Lee, M.G. Kesler, AIChE J. 1975, 21 (3), 510-527, DOI: 10.1002/aic.690210313 


\section{List of Tables}

Table 1 - Experimental process conditions.

Table 2 - Elementary steps of hydrocarbon formation in the Van der Laan and Beenackers model.

Table 3 - Additional elementary steps of hydrocarbon formation on secondary sites for Nowicki et al. model.

Table 4 - Comparison of selectivity models fitting according to MARR value.

Table 5 - Estimated parameters for extended Van der Laan and Beenackers model (with c parameter estimated from experimental data).

Table 6 - Estimated parameters for extended Van der Laan and Beenackers model (with c parameter from VLE calculations). 


\section{List of Figures}

Figure 1 - Reaction networks used in derivation of selectivity models.

Figure 2 - Comparison between experimental (points) and calculated product formation rates (lines) for a selected condition of: a) extended Van der Laan and Beenackers model; b) Nowicki et al. model.

Figure 3 - Extended Van der Laan and Beenackers model parity plots for total hydrocarbons.

Figure 4 - Comparison between experimental (points) and calculated product formation ratios (lines) for extended Van der Laan and Beenackers model at selected condition.

Figure 5 - Parity plot of grouped hydrocarbons (ORPDM with parameter c from VLE). 
Table 1

\begin{tabular}{|c|c|c|c|c|c|c|c|c|c|c|c|}
\hline \multirow{2}{*}{ Run } & \multirow{2}{*}{ MB } & \multirow{2}{*}{$\begin{array}{l}\text { TOS } \\
\text { (h) }\end{array}$} & \multirow{2}{*}{$\begin{array}{c}\mathrm{T} \\
\left({ }^{\circ} \mathrm{C}\right)\end{array}$} & \multirow{2}{*}{$\begin{array}{c}P \\
\text { (bar) }\end{array}$} & \multirow{2}{*}{$\begin{array}{c}\text { Inlet } \\
\mathrm{H}_{2} / \mathrm{CO}\end{array}$} & \multirow{2}{*}{$\begin{array}{c}\text { SV } \\
\mathrm{NL} /\left(\mathrm{g}_{\mathrm{Fe}}{ }^{*} h\right)\end{array}$} & \multirow{2}{*}{$\begin{array}{c}X_{C O} \\
\%\end{array}$} & \multirow{2}{*}{$\begin{array}{c}\mathbf{X}_{\mathrm{H} 2} \\
\%\end{array}$} & \multicolumn{3}{|c|}{ Selectivity (HC wt. \%) } \\
\hline & & & & & & & & & $\mathrm{CH}_{4}$ & $C_{2}-C_{4}$ & $C_{5+}$ \\
\hline \multirow{12}{*}{1} & 1 & 78 & 260 & 15 & 0.67 & 4.0 & 54 & 60 & 4.6 & 19.8 & 75.6 \\
\hline & 2 & 101 & 260 & 15 & 0.67 & 1.7 & 84 & 80 & 5.9 & 22.2 & 71.9 \\
\hline & 3 & 126 & 260 & 15 & 0.67 & 9.2 & 27 & 39 & 6.4 & 27.4 & 66.2 \\
\hline & 4 & 164 & 240 & 15 & 0.67 & 2.0 & 39 & 51 & 5.2 & 22.9 & 71.9 \\
\hline & 5 & 215 & 240 & 15 & 0.67 & 1.0 & 56 & 62 & 5.4 & 26.7 & 67.8 \\
\hline & 6 & 238 & 240 & 15 & 0.67 & 5.5 & 14 & 25 & 7.1 & 28.2 & 64.7 \\
\hline & $7 \mathrm{~b}$ & 270 & 260 & 15 & 0.67 & 4.0 & 46 & 54 & 5.3 & 22.5 & 72.2 \\
\hline & 8 & 310 & 240 & 15 & 2.00 & 4.2 & 46 & 29 & 11.2 & 36.0 & 52.8 \\
\hline & 9 & 368 & 240 & 15 & 2.00 & 10.8 & 22 & 15 & 10.1 & 33.9 & 56.0 \\
\hline & $10 \mathrm{~b}$ & 505 & 260 & 15 & 0.67 & 4.0 & 46 & 55 & 4.9 & 21.2 & 73.9 \\
\hline & 11 & 606 & 260 & 22.5 & 0.67 & 6.1 & 36 & 52 & 6.0 & 25.6 & 68.4 \\
\hline & 12 & 654 & 260 & 22.5 & 0.67 & 1.0 & 84 & 81 & 5.9 & 23.7 & 70.4 \\
\hline \multirow{9}{*}{2} & $b$ & 55 & 260 & 15 & 0.67 & 4.0 & 53.5 & 61.7 & 4.1 & 19.7 & 76.2 \\
\hline & 1 & 92 & 260 & 15 & 2.00 & 7.1 & 77 & 39 & 10.3 & 26.5 & 63.2 \\
\hline & 2 & 122 & 260 & 15 & 2.00 & 10.1 & 66 & 34 & 9.8 & 26.5 & 63.6 \\
\hline & 3 & 146 & 260 & 15 & 2.00 & 23.5 & 41 & 25 & 9.7 & 29.2 & 61.1 \\
\hline & 4 & 191 & 240 & 15 & 2.00 & 5.8 & 55 & 34 & 8.7 & 28.0 & 63.3 \\
\hline & 5 & 240 & 260 & 25 & 0.67 & 6.7 & 43 & 60 & 4.2 & 21.3 & 74.6 \\
\hline & 6 & 268 & 260 & 25 & 0.67 & 17.1 & 20 & 37 & 4.9 & 21.5 & 73.6 \\
\hline & 7 & 313 & 260 & 25 & 0.67 & 2.0 & 70 & 76 & 5.0 & 23.7 & 71.3 \\
\hline & b & 337 & 260 & 15 & 0.67 & 4.0 & 38.3 & 49.9 & 4.5 & 22.5 & 72.9 \\
\hline \multirow{10}{*}{3} & $b$ & 72 & 260 & 15 & 0.67 & 4.0 & 55.2 & 61.1 & 4.1 & 20.1 & 75.8 \\
\hline & 1 & 101 & 220 & 15 & 0.67 & 4.1 & 11 & 25 & 5.0 & 18.5 & 76.5 \\
\hline & 2 & 143 & 220 & 15 & 0.67 & 0.5 & 34 & 51 & 4.5 & 26.7 & 68.8 \\
\hline & 3 & 170 & 220 & 15 & 2.00 & 9.5 & 13 & 12 & 15.3 & 36.6 & 48.1 \\
\hline & 4 & 198 & 220 & 15 & 2.00 & 0.6 & 72 & 42 & 7.3 & 25.2 & 67.5 \\
\hline & 5 & 238 & 260 & 8 & 2.00 & 1.5 & 84 & 32 & 14.0 & 29.0 & 57.0 \\
\hline & 6 & 268 & 260 & 8 & 2.00 & 9.0 & 35 & 21 & 10.5 & 30.3 & 59.2 \\
\hline & 7 & 292 & 240 & 8 & 0.67 & 5.5 & 9 & 17 & 4.7 & 17.5 & 77.9 \\
\hline & 8 & 318 & 240 & 8 & 0.67 & 0.7 & 50 & 54 & 3.9 & 16.5 & 79.6 \\
\hline & $b$ & 341 & 260 & 15 & 0.67 & 4.0 & 40.8 & 51.5 & 3.7 & 18.2 & 78.1 \\
\hline
\end{tabular}

Note: MB - mass balance; TOS - time on stream; $S V$ - space velocity; $X$-conversion; $b$ - baseline replicate (data not used in parameter estimation). 


\section{Table 2}

\begin{tabular}{|c|c|c|}
\hline No. & Elementary reactions & Kinetic equations \\
\hline $\mathrm{HCl}$ & $\begin{array}{l}\text { Initiation - formation of adsorbed methyl species } \\
\mathrm{CH}_{2}-\mathrm{S}_{1}+\mathrm{H}-\mathrm{S}_{1} \stackrel{\mathrm{k}_{i}}{\longrightarrow} \mathrm{CH}_{3}-\mathrm{S}_{1}\end{array}$ & $r_{i}=k_{i} \cdot \theta_{C_{H_{2}-S_{1}}} \cdot \theta_{H-S_{1}}=\lambda_{1}$ \\
\hline $\mathrm{HC} 2$ & $\begin{array}{l}\text { Propagation } \\
\mathrm{C}_{n} \mathrm{H}_{2 n+1}-\mathrm{S}_{1}+\mathrm{CH}_{2}-S_{1} \stackrel{k_{p}}{\longrightarrow} \mathrm{C}_{n+1} H_{2 n+3}-S_{1} \\
n=1,2, \ldots\end{array}$ & $\begin{array}{l}r_{p}^{(n)}=k_{p} \cdot \theta_{C_{2}-S_{1}} \cdot \theta_{C_{n} H_{2 n+1}-S_{1}} \\
r_{p}^{(n)}=\lambda_{p} \cdot \theta_{C_{n} H_{2 n+1}-S_{1}} \\
\text { where } \\
\lambda_{p}=k_{p} \cdot \theta_{C_{2}-S_{1}}\end{array}$ \\
\hline $\mathrm{HC} 3$ & $\begin{array}{l}\text { Primary termination to n-paraffin (hydrogenation) } \\
C_{n} H_{2 n+1}-S_{1}+H-S_{1} \stackrel{k_{t, p}}{\longrightarrow} C_{n} H_{2 n+2}+2 S_{1} \\
n=1,2, \ldots\end{array}$ & $\begin{array}{l}r_{t, p}^{(n)}=k_{t, p} \cdot \theta_{H-S_{1}} \cdot \theta_{C_{n} H_{2 n+1}-S_{1}} \\
r_{t, p}^{(n)}=\lambda_{t, p} \cdot \theta_{C_{n} H_{2 n+1}-S_{1}} \\
\text { where } \\
\lambda_{t, p}=k_{t, p} \cdot \theta_{H-S_{1}}\end{array}$ \\
\hline $\mathrm{HC} 4$ & $\begin{array}{l}\text { Primary termination to } 1 \text {-olefin (dehydrogenation } \\
\text { and desorption) } \\
C_{n} H_{2 n+1}-S_{1}+S_{1} \stackrel{k_{t, 1 o}}{\longrightarrow} 1-C_{n} H_{2 n}+H-S_{1}+S_{1} \\
n=2,3, \ldots\end{array}$ & $\begin{array}{l}r_{t, 1 o}^{(n)}=k_{t, 1 o} \cdot \theta_{S_{1}} \cdot \theta_{C_{n} H_{2 n+1}-S_{1}} \\
r_{t, 1 o}^{(n)}=\lambda_{t, 1 o} \cdot \theta_{C_{n} H_{2 n+1}-S_{1}} \\
\text { where } \\
\lambda_{t, 1 o}=k_{t, 1 o} \cdot \theta_{S_{1}}\end{array}$ \\
\hline HC5 & $\begin{array}{l}\text { 1-olefin readsorption on primary sites } \\
1-C_{n} H_{2 n}+H-S_{1}+S_{1} \stackrel{k_{r, 1 o}}{\longrightarrow} C_{n} H_{2 n+1}-S_{1}+S_{1} \\
n=2,3, \ldots\end{array}$ & $\begin{array}{l}r_{r, 1 o}^{(n)}=k_{r, 1 o} \cdot \theta_{H-S_{1}} \cdot \theta_{S_{1}} \cdot C_{1-C_{n} H_{2 n}}^{S} \\
r_{r, 1 o}^{(n)}=\lambda_{r, 1 o}^{*} \cdot C_{1-C_{n} H_{2 n}}^{S} \\
\text { where } \\
\lambda_{r, 1 o}^{*}=k_{r, 1 o} \cdot \theta_{S_{1}} \cdot \theta_{H-S_{1}}\end{array}$ \\
\hline HC6 & $\begin{array}{l}\text { Primary termination to 2-olefin (dehydrogenation } \\
\text { and desorption) } \\
C_{n} H_{2 n+1}-S_{1}+S_{1} \stackrel{k_{t, 2 o}}{\longrightarrow} 2-C_{n} H_{2 n}+H-S_{1}+S_{1} \\
n=4,5, \ldots\end{array}$ & $\begin{array}{l}r_{t, 2 o}^{(n)}=k_{t, 2 o} \cdot \theta_{S_{1}} \cdot \theta_{C_{n} H_{2 n+1}-S_{1}} \\
r_{t, 2 o}^{(n)}=\lambda_{t, 2 o} \cdot \theta_{C_{n} H_{2 n+1}-S_{1}} \\
\text { where } \\
\lambda_{t, 2 o}=k_{t, 2 o} \cdot \theta_{S_{1}}\end{array}$ \\
\hline
\end{tabular}

Note: $S_{l}$ are the primary active sites, $\theta$ is the surface coverage of adsorbed species, $C^{S}$ is the concentration of a species on the surface. 


\section{Table 3}

\begin{tabular}{|c|c|c|}
\hline No. & Elementary reactions & Kinetic equations \\
\hline HC7 & $\begin{array}{l}\text { 1-olefin readsorption on secondary sites } \\
1-C_{n} H_{2 n}+H-S_{2}+S_{2} \stackrel{k_{s r}, 1 o}{\longrightarrow} C_{n} H_{2 n+1}-S_{2}+S_{2} \\
\mathrm{n}=2,3, \ldots\end{array}$ & $\begin{array}{l}r_{s r, 1 o}^{(n)}=k_{s r, 1 o} \cdot \theta_{H-S_{2}} \cdot \theta_{S_{2}} \cdot C_{1-C_{n} H_{2 n}}^{S} \\
r_{s r, 1 o}^{(n)}=\lambda_{s r, 1 o}^{*} \cdot C_{1-C_{n} H_{2 n}}^{S} \\
\text { where } \\
\lambda_{s r, 1 o}^{*}=k_{s r, 1 o} \cdot \theta_{S_{2}} \cdot \theta_{H-S_{2}}\end{array}$ \\
\hline HC8 & $\begin{array}{l}\text { Termination to n-paraffin (hydrogenation) on } \\
\text { secondary sites } \\
C_{n} H_{2 n+1}-S_{1}+H-S_{2} \stackrel{k_{t, p}}{\longrightarrow} C_{n} H_{2 n+2}+2 S_{2} \\
\mathrm{n}=2,3, \ldots\end{array}$ & $\begin{array}{l}r_{s t, p}^{(n)}=k_{s t, p} \cdot \theta_{H-S_{2}} \cdot \theta_{C_{n} H_{2 n+1}-S_{2}} \\
r_{s t, p}^{(n)}=\lambda_{s t, p} \cdot \theta_{C_{n} H_{2 n+1}-S_{2}} \\
\text { where } \\
\lambda_{s t, p}=k_{s t, p} \cdot \theta_{H-S_{2}}\end{array}$ \\
\hline HC9 & $\begin{array}{l}\text { Termination to 1-olefin (dehydrogenation) on } \\
\text { secondary sites } \\
C_{n} H_{2 n+1}-S_{2}+S_{2} \stackrel{k_{s t, 1 o}}{\longrightarrow} 1-C_{n} H_{2 n}+H-S_{2}+S_{2} \\
\mathrm{n}=4,5, \ldots\end{array}$ & $\begin{array}{l}r_{s t, 1 o}^{(n)}=k_{s t, 1 o} \cdot \theta_{S_{2}} \cdot \theta_{C_{n} H_{2 n+1}-S_{2}} \\
r_{s t, 1 o}^{(n)}=\lambda_{s t, 1 o} \cdot \theta_{C_{n} H_{2 n+1}-S_{2}} \\
\text { where } \\
\lambda_{s t, 1 o}=k_{s t, 1 o} \cdot \theta_{S_{2}}\end{array}$ \\
\hline $\mathrm{HC} 10$ & $\begin{array}{l}\text { Termination to 2-olefin (dehydrogenation) on } \\
\text { secondary sites } \\
\mathrm{C}_{n} H_{2 n+1}-S_{2}+S_{2} \stackrel{k_{s t, 2 o}}{\longrightarrow} 2-C_{n} H_{2 n}+H-S_{2}+S_{2}\end{array}$ & $\begin{array}{l}r_{s t, 2 o}^{(n)}=k_{s t, 2 o} \cdot \theta_{S_{2}} \cdot \theta_{C_{n} H_{2 n+1}-S_{2}} \\
r_{s t, 2 o}^{(n)}=\lambda_{s t, 2 o} \cdot \theta_{C_{n} H_{2 n+1}-S_{2}} \\
\text { where } \\
\lambda_{s t, 2 o}=k_{s t, 2 o} \cdot \theta_{S_{2}}\end{array}$ \\
\hline
\end{tabular}

Note: $S_{1}$ are the primary active sites, $S_{2}$ are the secondary active sites, $\theta$ is the surface coverage of adsorbed species, $\mathrm{C}^{\mathrm{S}}$ is the concentration of a species on the surface. 


\section{Table 4}

\begin{tabular}{|l|l|l|}
\hline & ORPDM & Nowicki et al. \\
\hline $220^{\circ} \mathrm{C}$ & 36 & 30 \\
\hline $240^{\circ} \mathrm{C}$ & 32 & 29 \\
\hline $260^{\circ} \mathrm{C}$ & 23 & 21 \\
\hline
\end{tabular}


Table 5

\begin{tabular}{|c|c|c|c|c|c|c|c|c|}
\hline \multicolumn{9}{|c|}{ Temperature: $220^{\circ} \mathrm{C}$} \\
\hline Run - MB & $\kappa_{1}$ & $\kappa_{p}$ & $\kappa_{t, 2 o}$ & $\kappa_{t, p}^{(1)}$ & $\kappa_{t, p}^{(2)}$ & $K_{10}^{(2)}$ & $K_{1 o}$ & $\mathrm{c}$ \\
\hline $3-1$ & 0.576 & 21.7 & \begin{tabular}{|l|l|}
0.207 \\
\end{tabular} & \multirow[t]{4}{*}{3.83} & \multirow[t]{4}{*}{0.882} & 6.86 & 13.2 & 0.214 \\
\hline $3-2$ & 0.222 & 12 & 0.319 & & & 3.16 & 10.3 & 0.194 \\
\hline $3-3$ & 0.982 & 7.27 & 0.16 & & & 2.02 & 5.68 & 0.163 \\
\hline $3-4$ & 0.337 & 9.5 & 0.218 & & & 1.14 & 5.33 & 0.209 \\
\hline \multicolumn{9}{|c|}{ Temperature: $240{ }^{\circ} \mathrm{C}$} \\
\hline Run - MB & $\kappa_{1}$ & $\kappa_{p}$ & \begin{tabular}{|l|}
$\kappa_{t, 2 o}$ \\
\end{tabular} & $\kappa_{t, p}^{(1)}$ & $\kappa_{t, p}^{(2)}$ & $K_{10}^{(2)}$ & $K_{10}$ & $\mathrm{c}$ \\
\hline $1-4$ & 0.924 & 20.4 & 0.448 & \multirow[t]{8}{*}{5.04} & \multirow[t]{8}{*}{1.65} & 5.32 & 11.9 & 0.229 \\
\hline $1-5$ & 0.653 & 11.3 & \begin{tabular}{|l|l|}
0.429 \\
\end{tabular} & & & 2.42 & 10.9 & 0.232 \\
\hline $1-6$ & 1.37 & 21.2 & \begin{tabular}{|l|l|}
0.398 \\
\end{tabular} & & & 6.87 & 14 & 0.256 \\
\hline $1-8$ & 2.6 & 9.26 & \begin{tabular}{|l|l|}
0.47 \\
\end{tabular} & & & 1.46 & 6.94 & 0.193 \\
\hline $1-9$ & 3.63 & 9.69 & 0.26 & & & 2.82 & 10.2 & 0.296 \\
\hline $2-4$ & 3.59 & 11.6 & \begin{tabular}{|l|l|}
0.313 \\
\end{tabular} & & & 1.93 & 8.34 & 0.259 \\
\hline $3-7$ & 0.745 & 39.1 & 0.5 & & & 8.42 & 11.2 & 0.221 \\
\hline $3-8$ & 0.324 & 32.2 & \begin{tabular}{|l|l|}
0.398 \\
\end{tabular} & & & 5.7 & 14.2 & 0.231 \\
\hline \multicolumn{9}{|c|}{ Temperature: $260{ }^{\circ} \mathrm{C}$} \\
\hline Run - MB & $\kappa_{1}$ & $\kappa_{p}$ & $\kappa_{t, 2 o}$ & $\kappa_{t, p}^{(1)}$ & $\kappa_{t, p}^{(2)}$ & $K_{10}^{(2)}$ & $K_{10}$ & $\mathrm{c}$ \\
\hline $1-1$ & 2.65 & 21.2 & 0.539 & \multirow[t]{15}{*}{6.84} & \multirow[t]{15}{*}{1.87} & 4.32 & 12.5 & 0.23 \\
\hline $1-2$ & 1.83 & 13 & 0.682 & & & 0.938 & 6.81 & 0.216 \\
\hline $1-3$ & 3.9 & 24.6 & 0.484 & & & 6.41 & 14.1 & 0.236 \\
\hline $1-7$ & 2.6 & 19.7 & \begin{tabular}{|l|l|}
0.537 \\
\end{tabular} & & & 4.2 & 11.8 & 0.237 \\
\hline $1-10$ & 2.55 & 19.5 & \begin{tabular}{|l|l|}
0.564 \\
\end{tabular} & & & 3.79 & 12.2 & 0.238 \\
\hline $1-11$ & 3.37 & 24.5 & 0.497 & & & 5.2 & 11.2 & 0.217 \\
\hline $1-12$ & 1.47 & 14.4 & 0.581 & & & 1 & 5.8 & 0.204 \\
\hline $2-1$ & 6.41 & 11.2 & 0.301 & & & 1.12 & 6.09 & 0.266 \\
\hline $2-2$ & 7.98 & 12.8 & 0.332 & & & 1.55 & 7.56 & 0.267 \\
\hline $2-3$ & 12.3 & 13.8 & 0.328 & & & 2.75 & 9.76 & 0.256 \\
\hline $2-5$ & 3.75 & 24.5 & 0.286 & & & 5.31 & 15.3 & 0.219 \\
\hline $2-6$ & 5.91 & 24.8 & $\mid 0.311$ & & & 5.34 & 12.7 & 0.191 \\
\hline $2-7$ & 1.63 & 18.8 & 0.447 & & & 2.76 & 9.72 & 0.185 \\
\hline $3-5$ & 1.45 & 7.22 & 0.45 & & & 0.283 & 2.35 & 0.161 \\
\hline $3-6$ & 3.28 & 11.6 & \begin{tabular}{|l|l|}
0.478 \\
\end{tabular} & & & 3.05 & 11.4 & 0.262 \\
\hline
\end{tabular}


Table 6

\begin{tabular}{|c|c|c|c|c|c|c|c|c|}
\hline \multicolumn{9}{|c|}{ Temperature: $220^{\circ} \mathrm{C}$} \\
\hline Run - MB & $\kappa_{1}$ & $\kappa_{p}$ & $\kappa_{t, 2 o}$ & $\kappa_{t, p}^{(1)}$ & $\kappa_{t, p}^{(2)}$ & $K_{10}^{(2)}$ & $K_{1 o}$ & $\mathrm{c}$ \\
\hline $3-1$ & 0.577 & 19.8 & 0.201 & \multirow[t]{4}{*}{2.89} & \multirow[t]{4}{*}{0.663} & 8.81 & 34.9 & 0.343 \\
\hline $3-2$ & 0.218 & 9.25 & 0.286 & & & 3.78 & 23.6 & 0.339 \\
\hline $3-3$ & 0.97 & 5.32 & \begin{tabular}{|l|l|}
0.163 \\
\end{tabular} & & & 2.48 & 14 & 0.352 \\
\hline $3-4$ & 0.329 & 7.72 & 0.216 & & & 1.42 & 12.4 & 0.375 \\
\hline \multicolumn{9}{|c|}{ Temperature: $240{ }^{\circ} \mathrm{C}$} \\
\hline Run - MB & $\kappa_{1}$ & $\kappa_{p}$ & \begin{tabular}{|l|}
$\kappa_{t, 2 o}$ \\
\end{tabular} & $\kappa_{t, p}^{(1)}$ & $\kappa_{t, p}^{(2)}$ & $K_{10}^{(2)}$ & $K_{1 o}$ & $\mathrm{c}$ \\
\hline $1-4$ & 0.945 & 18.6 & 0.436 & \multirow[t]{8}{*}{4.54} & \multirow[t]{8}{*}{1.48} & 6.3 & 24.9 & 0.373 \\
\hline $1-5$ & 0.658 & 10 & \begin{tabular}{|l|}
0.391 \\
\end{tabular} & & & 2.83 & 19.7 & 0.381 \\
\hline $1-6$ & 1.39 & 19.6 & \begin{tabular}{|l|}
0.391 \\
\end{tabular} & & & 7.96 & 26.2 & 0.346 \\
\hline $1-8$ & 2.62 & 7.85 & \begin{tabular}{|l|l|}
0.457 \\
\end{tabular} & & & 1.7 & 13.7 & 0.362 \\
\hline $1-9$ & 3.61 & 9.06 & 0.258 & & & 2.95 & 13 & 0.352 \\
\hline $2-4$ & 3.6 & 10.5 & 0.308 & & & 2.2 & 14.1 & 0.348 \\
\hline $3-7$ & 0.793 & 38.5 & \begin{tabular}{|l|l|}
0.497 \\
\end{tabular} & & & 10.5 & 30.4 & 0.349 \\
\hline $3-8$ & 0.341 & 32.3 & \begin{tabular}{|l|}
0.391 \\
\end{tabular} & & & 7.09 & 34.2 & 0.342 \\
\hline \multicolumn{9}{|c|}{ Temperature: $260{ }^{\circ} \mathrm{C}$} \\
\hline Run - MB & $\kappa_{1}$ & $\kappa_{p}$ & $\kappa_{t, 2 o}$ & $\kappa_{t, p}^{(1)}$ & $\kappa_{t, p}^{(2)}$ & $K_{10}^{(2)}$ & $K_{10}$ & $\mathrm{c}$ \\
\hline $1-1$ & 2.74 & 20.4 & 0.524 & \multirow[t]{15}{*}{6.46} & \multirow[t]{15}{*}{1.75} & 4.96 & 22.9 & 0.351 \\
\hline $1-2$ & 1.85 & 12 & 0.663 & & & 1.05 & 12.1 & 0.353 \\
\hline $1-3$ & 4.04 & 24 & 0.472 & & & 7.48 & 26.9 & 0.328 \\
\hline $1-7$ & 2.67 & 18.8 & 0.525 & & & 4.79 & 21.1 & 0.377 \\
\hline $1-10$ & 2.61 & 18.6 & 0.546 & & & 4.36 & 21.6 & 0.343 \\
\hline $1-11$ & 3.54 & 23.9 & 0.488 & & & 6.19 & 24.1 & 0.344 \\
\hline $1-12$ & 1.52 & 13.4 & 0.575 & & & 1.13 & 11.9 & 0.34 \\
\hline $2-1$ & 6.46 & 10.7 & 0.299 & & & 1.24 & 9.2 & 0.406 \\
\hline $2-2$ & 8.06 & 12.2 & \begin{tabular}{|l|}
0.329 \\
\end{tabular} & & & 1.71 & 11.6 & 0.402 \\
\hline $2-3$ & 12.4 & 13.3 & 0.323 & & & 2.98 & 14.1 & 0.408 \\
\hline $2-5$ & 3.91 & 26.5 & 0.265 & & & 6.82 & 32.3 & 0.406 \\
\hline $2-6$ & 6.24 & 27.6 & \begin{tabular}{|l|}
0.291 \\
\end{tabular} & & & 7.3 & 32.5 & 0.315 \\
\hline $2-7$ & 1.71 & 18.6 & 0.41 & & & 3.46 & 23 & 0.316 \\
\hline $3-5$ & 1.46 & 6.6 & 0.441 & & & 0.282 & 4.57 & 0.382 \\
\hline $3-6$ & 3.3 & 11 & \begin{tabular}{|l|l|}
0.468 \\
\end{tabular} & & & 3.21 & 14.5 & 0.38 \\
\hline
\end{tabular}


Figure 1

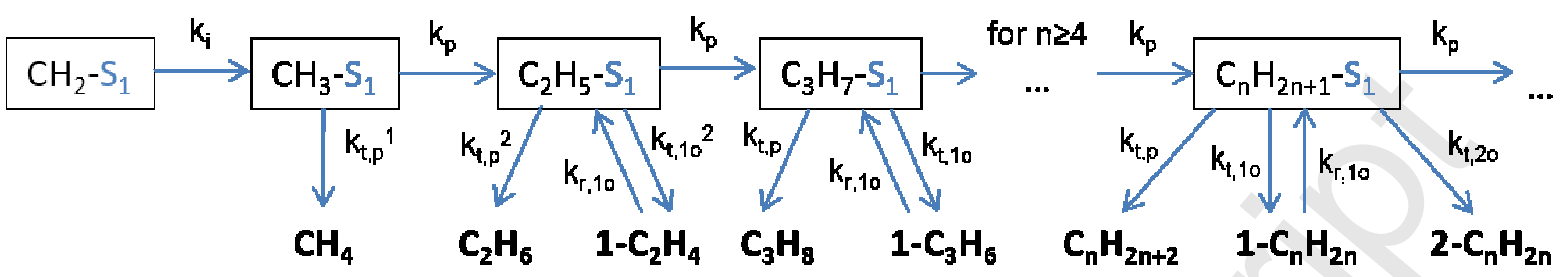

a) Van der Laan and Beenackers (1999) (extended with 2-olefin formation)

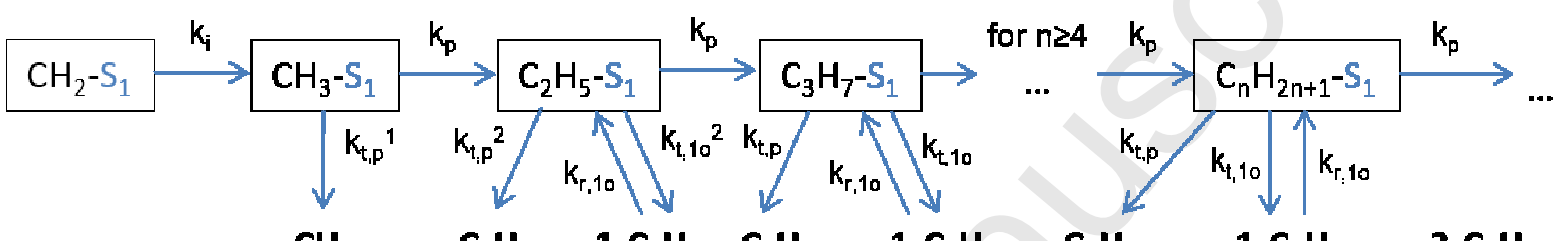

b) Nowicki et al. (2001)

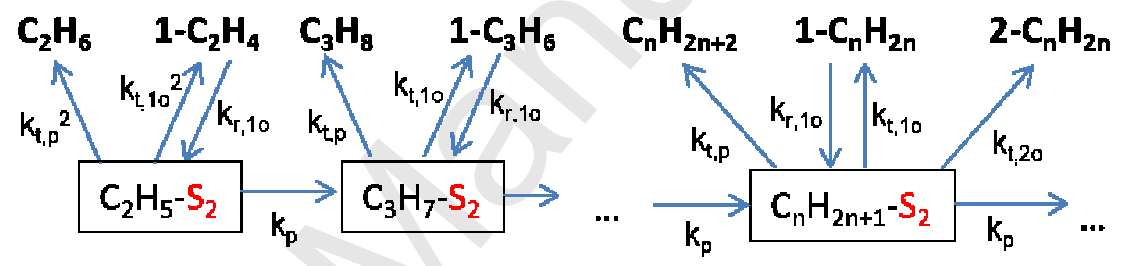


Figure 2
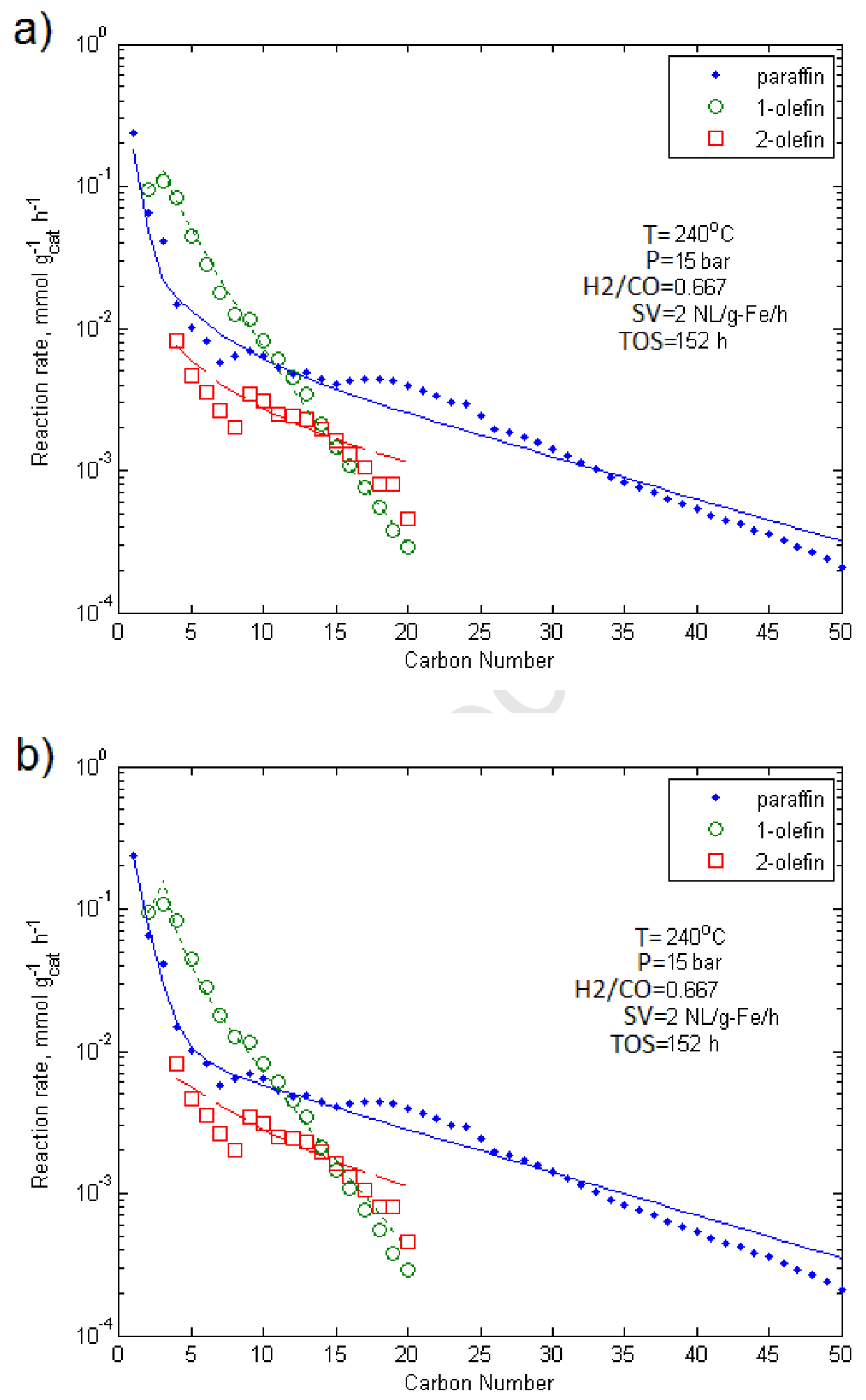
Figure 3

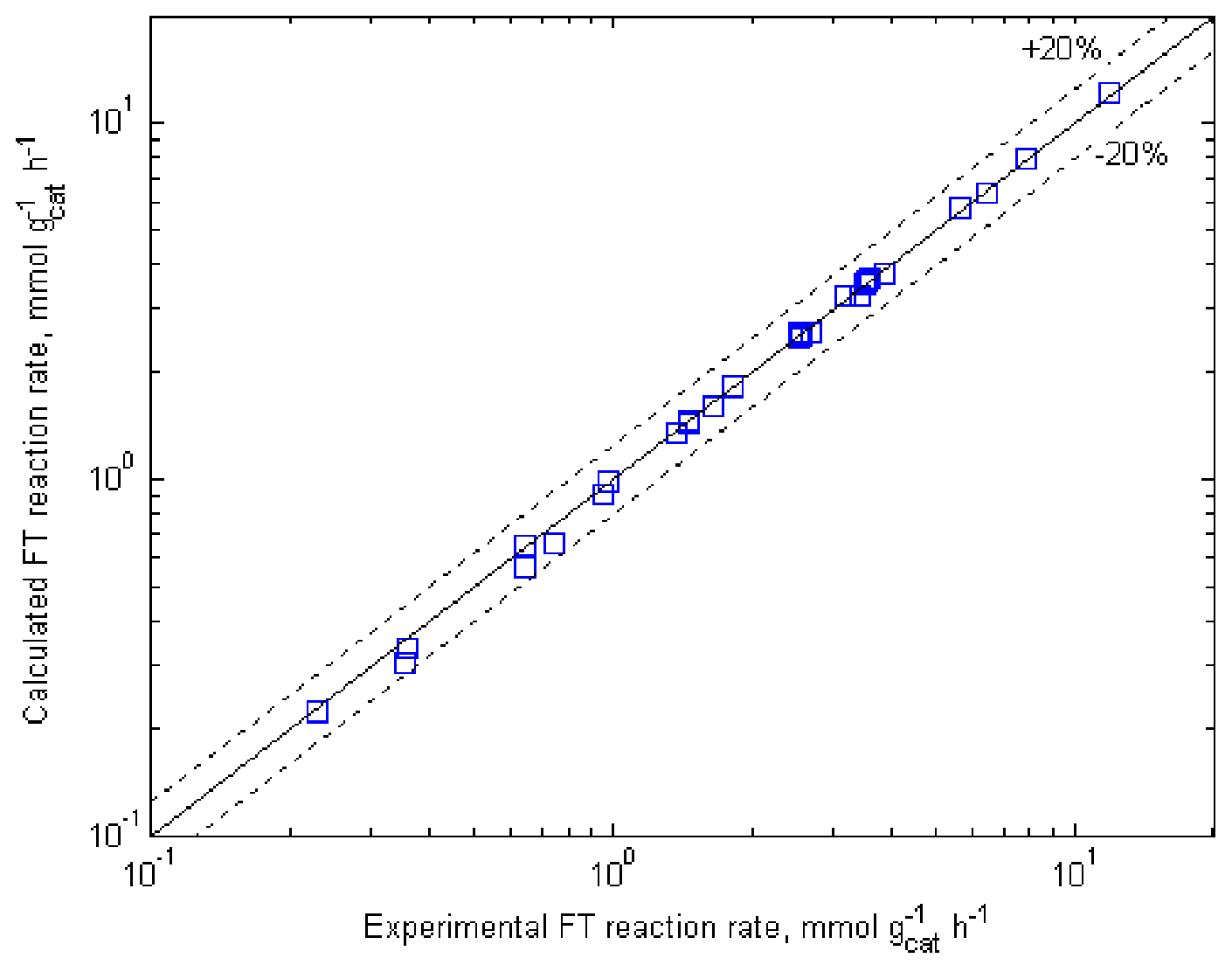


Figure 4

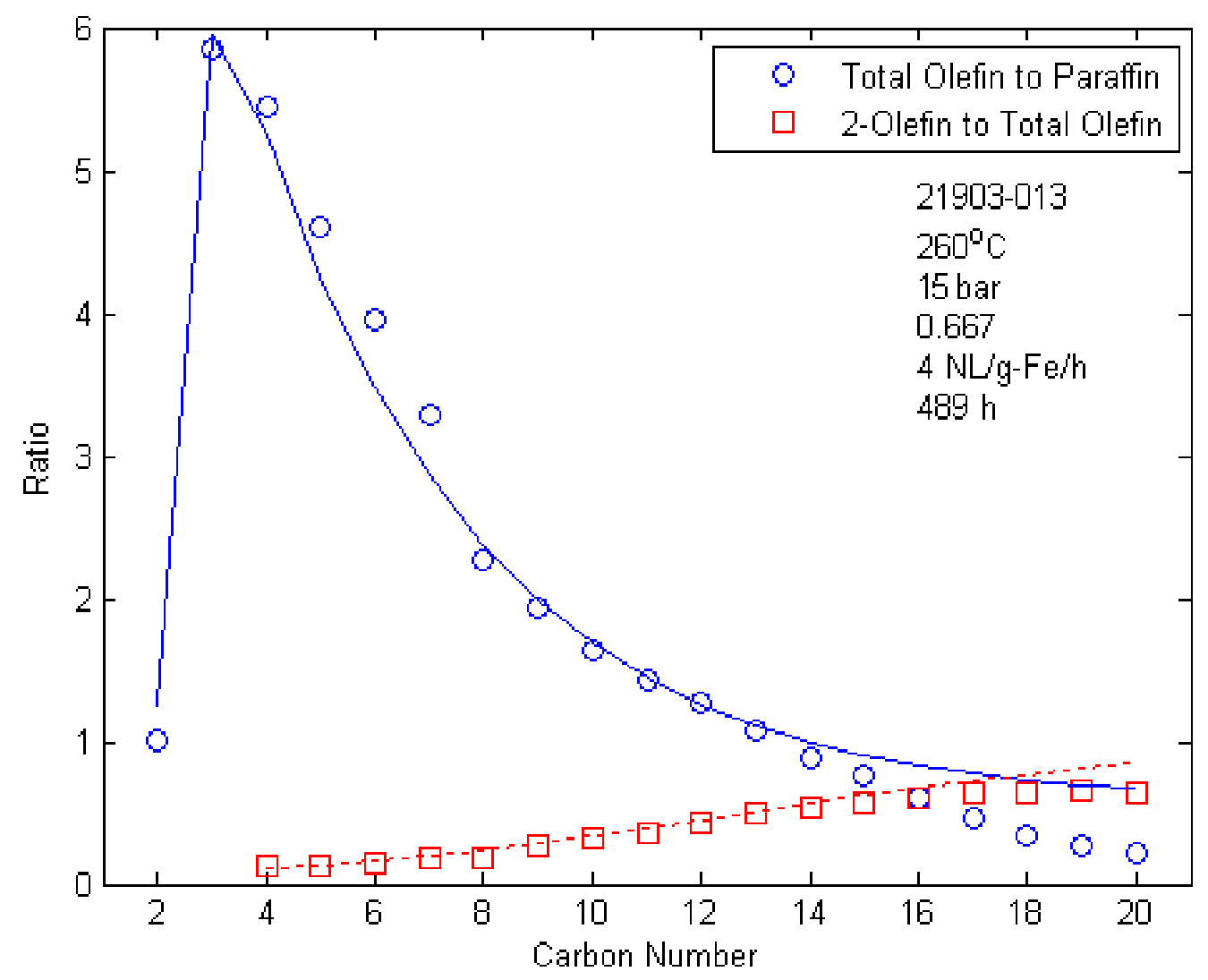


Figure 5

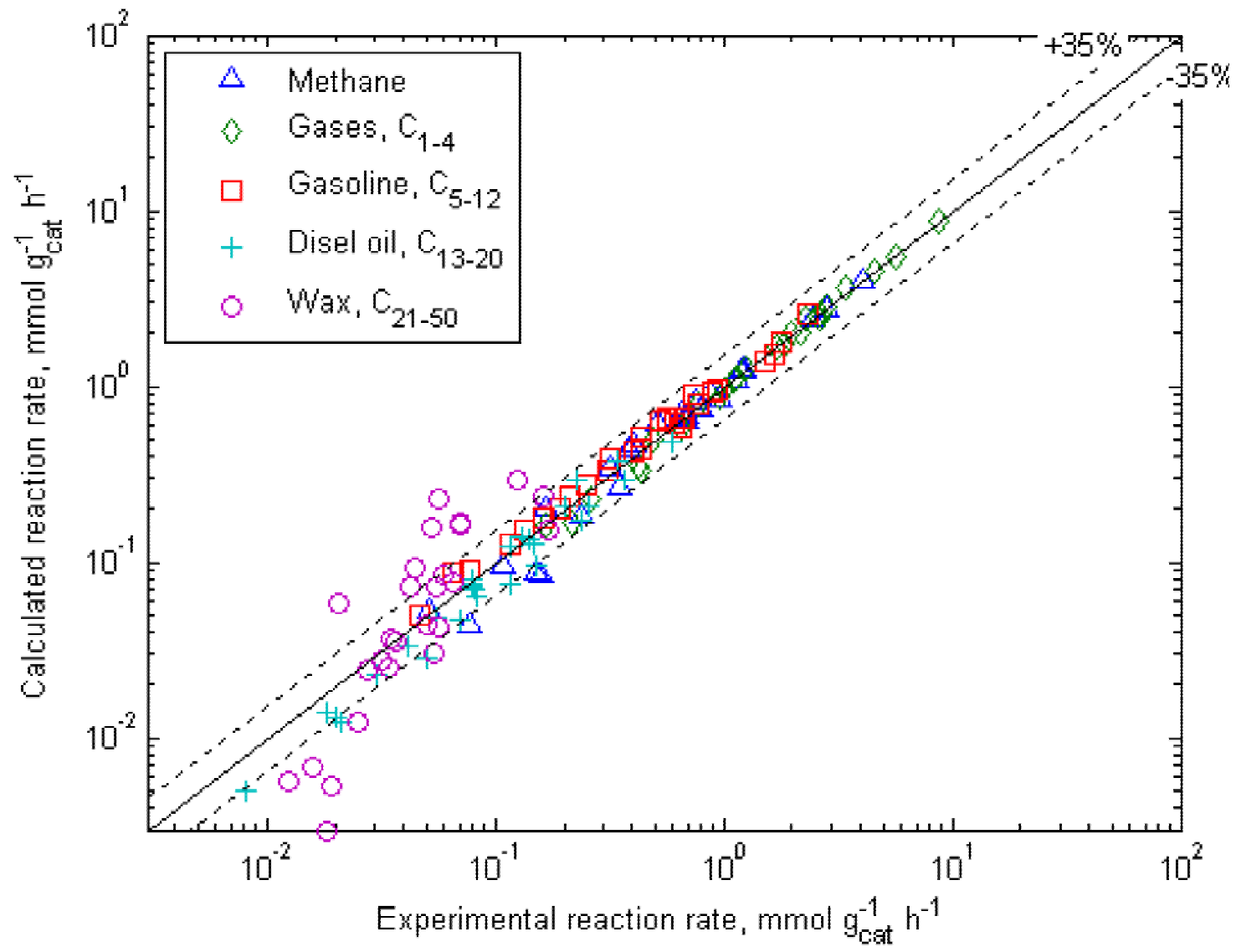




\section{FTS reaction network}

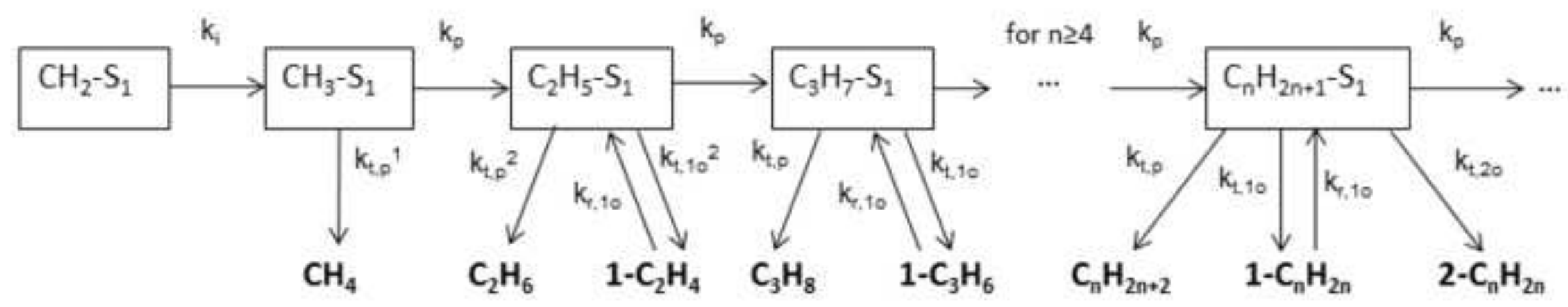

Extended Van der Laan and Beenackers model 